\title{
Ti-Si-O 多孔玻璃在低烧结温度下的析晶现象*
}

\author{
刘卫国 孔令兵张良莹姚喜

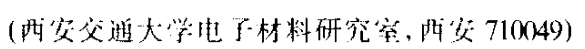

\section{关键词溶胶 - 凝胶 多孔玻璃 $\mathrm{X}$ 射线衍射}

随着㩁胶 - 凝胶制备技术的发展, 具有纳米级微孔的多孔二氧化硅玻璃作为纳米复合的 拍体, 已显示出其独特的优势. 将活性组元植入微孔中所得复合材料, 在光学非线性、传感。

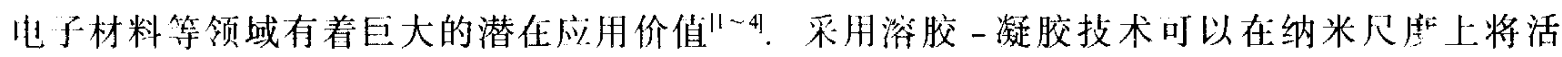
㨫组元分散到多孔二氧化硅中，通过人小效应使复合材料早现出特异的性质. $\mathrm{TiO}_{2}$ 是一种弱

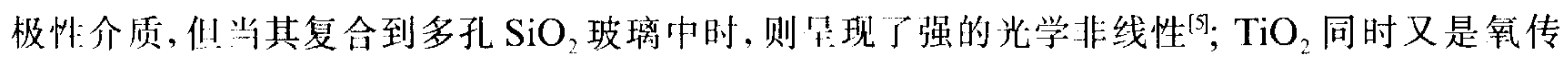
感器的良好材料, 其多变的结唱结构提供了不同的应用背景。研究 $\mathrm{TiO}_{2}$ 在多孔 $\mathrm{SiO}_{2}$ 中的结 晶行为无疑会为其应用提供良好的基础.

由丁.多孔 $\mathrm{SiO}_{2}$ 中的孔径是纳米级的, 活性: 组元在其中的生长将是受限的; 同时由于活性 组儿在其中是高度分散的, 最终的唱粒大度也往往在纳米大度. 掺人 $\mathrm{TiO}_{2}$ 店, $\mathrm{TiO}_{2}$ 的析晶有 川能诱导 $\mathrm{SiO}_{2}$ 的析晶, 二种析唱过程会产生彼此的竞争, 其优劣程度将取决于热环境、 $\mathrm{TiO}_{2}$ 的 掺杂量、 $\mathrm{TiO}_{2}$ 的分散程度等; 在不同的热环境卜, $\mathrm{TiO}_{2}$ 的晶型是不同的. 本文的 $\mathrm{H}$ 的, 是观察 在较低烧结温度 $\left(<1000^{\circ} \mathrm{C}\right)$ 下, 即在保持多孔性的前提下, $\mathrm{Ti}-\mathrm{Si}-\mathrm{O}$ 玻璃中的析奛现象, 研究了 不同热处理温度, 不同 $\mathrm{TiO}_{2}$ 掺杂量对析晶过程的影响。

\section{1 实验}

采用改进的浴胶 - 凝胶工艺制备掺 $\mathrm{TiO}_{2}$ 的 $\mathrm{SiO}_{2}$ 凝胶. 制备过程为: 将比例为 1:4:4:0.03 的正硅酸 酯 (分析纯)、无水乙醇 (分析纯)、去漓子水和盐酸充分混合得 $\mathrm{SiO}_{2}$ 先体, 试剂量的

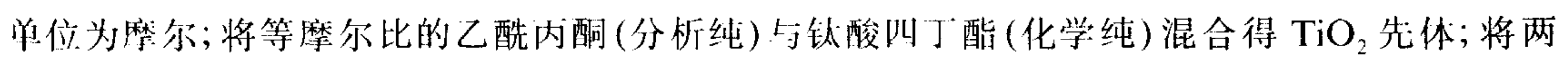
种先体挍所需比例韲合, 经陈化、 50 C 下凝胶成块。配制了 $\mathrm{TiO}_{2}$ 的摩尔系数为 $5 \%, 10 \%$ 利 $20 \%$ 们 Ti-Si-O 凝胶, 分别记为 TS5, TS 10 和 $\mathrm{TS} 20$.

以 $1{ }^{\circ} \mathrm{C} / \mathrm{min}$ 的加热速度分别把三种组分的凝胶加热至 $610^{\circ} \mathrm{C}$ 和 $950^{\circ} \mathrm{C}$, 并分别保温 $1 \mathrm{~h}$, 得 实验样品. 把 $610^{\circ} \mathrm{C}$ 烧结的样品记为 TS56、TS106 和 TS206; 把 $950^{\circ} \mathrm{C}$ 烧结的样品记为 TS59, TS109 和 RS209. 用日本理学的 D/msx-2400 型 X 射线衍射仪对样品结构进行分析, 射线源为 $\mathrm{CuK}-\alpha \mathrm{l}$, 㹊电庈为 $44 \mathrm{kV}$, 管电流为 $120 \mathrm{~mA}$, 扫描步长为 $0.02^{\circ}$. 


\section{2 结果与讨论}

$610^{\circ} \mathrm{C}$ 和 $950^{\circ} \mathrm{C}$ 下处理的样品的 XRD 谱分别示于图 1 和图 2. 通过 JCPDS 卡片核对了 各衍射峰对应的晶相.

图 1 中用 “O”符号示出了 $\mathrm{TiO}_{2}$ 的衍射峰, 峰的弥散提示了晶粒极为细小. 由于峰的弥 散, 无法确定其晶型, 但仍可判定其应属 $\mathrm{TiO}_{2}$ 的低温相板钛矿或锐钛矿结构, 而不是金红石 相.

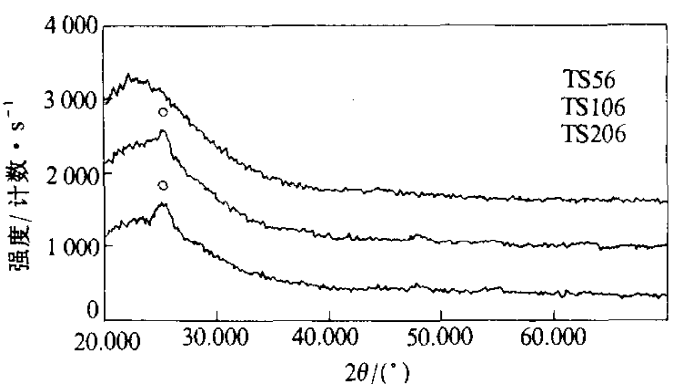

图 $1610^{\circ} \mathrm{C}$ 烧结样品的 XRD 谱

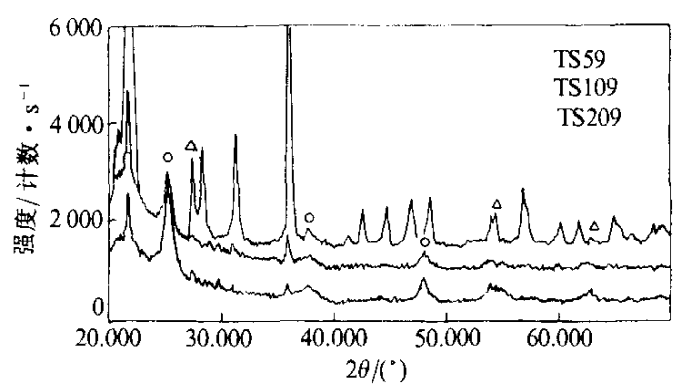

图 $2950^{\circ} \mathrm{C}$ 烧结样品的 XRD 谱

从图 1 可见, 当 $\mathrm{TiO}_{2}$ 含量增加时, $\mathrm{TiO}_{2}$ 的析晶倾向增强, 在其 $\mathrm{TiO}_{2}$ 的摩尔系数为 $5 \%$ 时, $\mathrm{Ti}-\mathrm{Si}-\mathrm{O}$ 呈非晶特征. 在某些应用场合, 如绝热应用时保持非晶态是有益的. 含量变化时 $\mathrm{TiO}_{2}$ 析晶性质 的差异也可以从样品的外观上反映出来. 对 TS56, 烧结后为无色透明块体; TS106 为半透明 浅灰色; 而 TS209 则为半透明较深灰色. 色泽上的变化是与 $\mathrm{Ti}$ 的价态和 $\mathrm{TiO}_{2}$ 的晶型相关 的.

图 1 给出这样的结论: 低烧结温度时, 随着含量的增加, $\mathrm{TiO}_{2}$ 微小晶粒会首先析出, 用 XRD 方法不能检出 $\mathrm{SiO}_{2}$ 的析晶.

图 2 中未标注峰均为 $\mathrm{SiO}_{2}$ 的衍射峰, 分别用 “ $O$ ” 和 “ $\triangle$ ” 符号标示出板钛矿和金红石结构 的 $\mathrm{TiO}_{2}$ 的衍射峰. 从图中可以看出 $\mathrm{TiO}_{2}$ 含量变化时衍射峰的明显差异.

纯相 $\mathrm{SiO}_{2}$ 的析晶通常要在 $1000^{\circ} \mathrm{C}$ 以上的烧结温度下才会发生, 而从图 2 可以明显地看 到, 由于 $\mathrm{TiO}_{2}$ 的掺人, $\mathrm{SiO}_{2}$ 在 $950^{\circ} \mathrm{C}$ 下即有完整地析晶发生. 结合图 1 的结果, $\mathrm{TiO}_{2}$ 是 $\mathrm{SiO}_{2}$ 的良好的析晶成核剂, 微小的 $\mathrm{TiO}_{2}$ 晶核促使了 $\mathrm{SiO}_{2}$ 的结晶化. 一个值得注意的有趣现象 是: 在低 $\mathrm{TiO}_{2}$ 含量 (如 $5 \mathrm{~mol} \%$ ) 下, $\mathrm{Ti}-\mathrm{Si}-\mathrm{O}$ 多孔玻璃随着烧结温度的升高, 会析出大量 $\mathrm{SiO}_{2}$ 晶粒; 当 $\mathrm{TiO}_{2}$ 含量升高时, $\mathrm{SiO}_{2}$ 虽然仍会析晶, 但衍射峰数目明显减少, 峰强减弱, 峰呈现弥 散倾向, 提示 $\mathrm{SiO}_{2}$ 的晶粒细化, 结晶结构出现某种不完整性. 这种现象是由多孔 $\mathrm{SiO}_{2}$ 中大量 均匀细微的孔结构所造成的. 由溶胶一凝胶法制备 $\mathrm{Ti}-\mathrm{Si}-\mathrm{O}$ 多孔玻璃时, $\mathrm{TiO}_{2}$ 是高度均匀地 分散于 $\mathrm{SiO}_{2}$ 中的, 当 $\mathrm{TiO}_{2}$ 含量较低时, 它首先会在 $-\mathrm{Si}-\mathrm{O}-\mathrm{Si}-\mathrm{O}-$ 网络中析出均匀微小的晶 核, 这是图 1 给出的结果; 由于 $\mathrm{TiO}_{2}$ 的低含量, 由扩散控制的晶粒生长过程受到 $-\mathrm{Si}-\mathrm{O}-$ 孔壁 网络结构的限制, 小尺寸的 $\mathrm{TiO}_{2}$ 晶核变成为 $\mathrm{SiO}_{2}$ 的析晶促进剂, 于是在 TS59 中得到大量的 $\mathrm{SiO}_{2}$ 晶粒. 当 $\mathrm{TiO}_{2}$ 含量升高时, $\mathrm{SiO}_{2}$ 网络的限域作用减弱, $\mathrm{TiO}_{2}$ 晶核得以长大, 同时一部分 晶核仍促进了 $\mathrm{SiO}_{2}$ 在较低温度下的结晶.

从图 2 还可看出, 随 $\mathrm{TiO}_{2}$ 含量的升高, $\mathrm{SiO}_{2}$ 的结晶受到抑制, $\mathrm{TiO}_{2}$ 与 $\mathrm{SiO}_{2}$ 的结晶呈现出 
“竞争”的特征.

$\mathrm{TiO}_{2}$ 从 $\mathrm{Ti}-\mathrm{Si}-\mathrm{O}$ 多孔玻璃中会以不同晶型析出, 低含量时金红石结构占优势, 随含量升 高, 板钠矿含量增加, 这反映在衍射峰的消长上.

由于多孔 $\mathrm{SiO}_{2}$ 的孔结构特征, 使 $\mathrm{Ti}-\mathrm{Si}-\mathrm{O}$ 的析晶呈现多样化, 合理控制 $\mathrm{TiO}_{2}$ 掺人量及热 处理条件, 可以得到不同应用所要求的结唱结构.

\section{参 考 文 献}

1 Nogues J R, Moreshead W V. Porous gel-silica, a matrix for optically active components. J Noncrystalline Solids, 1990, $121(1): 136 \sim 142$

2 Komarneni S, Roy R, Selvaraj U et al. Nanocomposite aerogels: the $\mathrm{SiO}_{2}-\mathrm{Al}_{2} \mathrm{O}_{3}$ systems. J Matter Res, 1993, 8(I2): $3157 \sim 3163$

3 Shafer M W, Awschalom D D, Warnock J. The chemistry of and physics with porous solgel glasses. J Appl Phys, 1987, 61 (12): $5438 \sim 5446$

4 Lu Sheng-guo, Xie Qing-yun, Zhang Liang-ying et al. Preparation and quantum size effect of semiconductor CdS doped silica glass $0 \sim 3$ nanocomposites through sol-gel process. Chinese Science Bulletin, 1994, 39(2): 96 100

5 周歧发, 韩 玉, 邹 秦等. PT-ER 精细复合材料的光学特性研究. 科学通报, 1992, 37(7): 665 667 